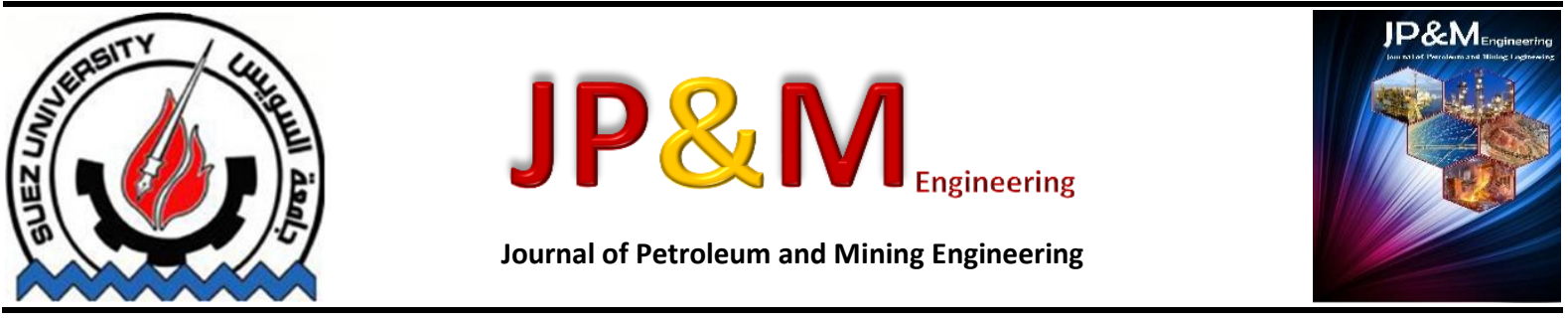

\title{
A Statistical Model for Hole Cleaning and Cuttings Transport Efficiency During Drilling of Wells
}

\author{
M. Reda ${ }^{a}$, N. A. El Sayed ${ }^{b}$, S. E. Shalaby ${ }^{b}$, M.S. Farahat ${ }^{\text {b }}$ \\ a Gulf of Suez Petroleum Company (GUPCO). \\ b Petroleum Engineering Department, Suez University.
}

\section{Keywords}

Hole cleaning; cuttings transport; Dimensional analysis technique; statistical regression model; Buckingham Pi theorem; least square fitting method; hole cleaning efficiency.

\begin{abstract}
This paper is about evaluating the minimum efficiency of hole cleaning and cuttings transport during drilling of vertical and deviated wells by a statistical-regression model using the Buckingham Pi theorem of dimensional analysis technique. The model will be evaluated by deriving the unknown proportionality constant and five exponents utilizing the statistical - regression curve of the least- squares fitting method and using the prepared field data from five drilled wells in the Gulf of Suez Company (GUPCO) fields. Then, the model's equation will be differentiated partially with respect to one of the independent parameters which are average annular velocity of drilling fluid, drilling rate of penetration, drill string rotation, drilling fluid density, yield point, plastic viscosity, density of drilled-cuttings, and coefficient related to hole deviation angle. Then it will be evaluated over a range of values for these parameters. From the parametric study, it is found that the hole cleaning efficiency increases as the average annular velocity, yield point, plastic viscosity, drill string rotation, density of drilling fluid increase. It is found also that efficiency decreases when drilling rate, cuttings density, hole deviation angle increase. Finally, it is recommended that the model can be applied in oil well drilling industry in different fields and horizontal wells rather than the vertical and deviated wells used in the paper.
\end{abstract}

\section{Introduction}

There are several problems encountered in deviated wells regarding hole cleaning because of cuttings accumulation at the low side of eccentric annulus. Poor hole cleaning can lead to many drilling problems including: hole pack-off, excessive equivalent circulation density (ECD), formation break down, higher torque and drags and decreasing drilling rate. However, the key to a successful hole cleaning relies upon integrating optimum drilling fluid properties with best drilling practices.

From previous investigations (1-14) about hole cleaning, the most important factors affecting hole cleaning and cuttings transport or the carrying capacity of drilling fluids are Annular velocity of drilling fluid, Hole deviation angle, Properties of drilling fluids, Rate of penetration, Pipe/hole eccentricity, Hole geometry, Annular velocity profile, Particle density, slip or settling velocity, size, and geometry, Rotary speed of drill pipe, and Pipe/hole diameter ratio.

Therefore, this paper is about developing a statistical model to predict the minimum efficiency of hole cleaning of deviated wells during drilling from sea bed or mud line until the end of pay zone. To achieve this objective, a five-step approach was adapted, namely:

- Applying all theoretical and physical considerations to develop the physical relationship between the hole cleaning and cuttings transport efficiency and its independent parameters.

- Applying the Buckingham $\mathrm{Pi}$ theorem (1) of dimensional analysis technique to derive the model's equation for cuttings transport efficiency.

- The unknown coefficient, $C$, and four exponents, a, b, c, d, and e added by dimensional analysis technique to the derived mathematical equation of cuttings transport efficiency, were determined by utilizing the statistical-regression curve of the least - squares fitting method through the field data. These field data were prepared by the author from five drilled-deviated wells in the Gulf of Suez field.

- The developed model's equation for hole cleaning efficiency was studied parametrically by applying the partial differentiation principles. 
- Also, the determination of the validity and generality of the developed hole cleaning efficiency model for applying in all geographical drilling regions, was recommended.

\section{Developing mathematical model}

\section{The minimum or effective efficiency of annular drilled-cuttings transport}

The minimum efficiency of drilled-cuttings transport is achieved in drilling deviated wells. Numerically, it equals the ratio between the minimum feed concentration of drilled-cuttings received on shale shaker at the surface and the maximum concentration of drilled-cuttings in the eccentric annulus of deviated wells. From previous studies (1-4, $7-9,12,13)$ performed on cuttings transport and mud flow in annuli of wellbores, it was found that the minimum drilled cuttings transport efficiency is a function of a number of parameters, namely:

- Average annular Velocity of drilling fluid (V).

- Drilling fluid parameters (plastic viscosity (PV), yield point $(\boldsymbol{Y p})$ and mud weight $\left.\left(\boldsymbol{\rho}_{\boldsymbol{m}}\right)\right)$.

- Hole angle factor $\left(\boldsymbol{G}=\mathbf{1}+\frac{\boldsymbol{\theta} \times \boldsymbol{\pi}}{\mathbf{1 8 0}}\right)$.

- Drilling rate $(\boldsymbol{R})$.

- Pipe rotation speed (RPM).

- Equivalent size or diameter of drilled-cuttings which is a function of shape or surface sphericity of these cuttings, $(\boldsymbol{d c})$.

- Density of drilled cuttings $\left(\boldsymbol{\rho}_{c}\right)$.

\section{Derivation of the model for hole cleaning efficiency in the annuli of deviated wells during drilling}

The major factors or parameters which affect the drilled-cuttings processes during drilling a deviated well, have been established or modeled into a mathematical equation or model using the Buckingham Pi theorem (equation 1 ),

$\emptyset\left(\boldsymbol{\eta}, P V, Y \boldsymbol{Y}, \boldsymbol{R}, \boldsymbol{R P M}, \boldsymbol{\rho}_{m}, \boldsymbol{\rho}_{\boldsymbol{c}}, \boldsymbol{d}_{\boldsymbol{c}}, \mathrm{G}, \mathrm{V}\right)=\mathbf{0}$

Here is the summary of steps for the model formulation. Thus, the equation can be mathematically equated to zero by including the dependent parameter $\boldsymbol{\eta}$ as an independent parameter, therefore, applying the Buckingham $\mathrm{Pi}$ theorem to solve. Thus, the equation (equation 2) includes six dimensionless groups. Hence, it can be written in this form:

Where:

$$
\varnothing\left(\pi_{1}, \pi_{2}, \pi_{3}, \pi_{4}, \pi_{5}, \pi_{6}\right)=0
$$

$$
\begin{aligned}
\pi_{1} & =\boldsymbol{\eta} \\
\pi_{2} & =\frac{\boldsymbol{Y} \boldsymbol{p}}{\boldsymbol{R}^{2} \boldsymbol{\rho}_{c}} \\
\pi_{3} & =\frac{\rho_{c}}{\rho_{m}} \\
\pi_{4} & =G \\
\pi_{5} & =\frac{\mathbf{P V} \times \mathbf{R P M}}{\mathbf{Y P}} \\
\pi_{6} & =\frac{\mathbf{V}}{\boldsymbol{R}}
\end{aligned}
$$

Therefore, the appropriate expression obtained by the Buckingham Pi theorem for solving this problem is given as follows (equation 3 ):

$$
\phi\left(\eta,\left(\frac{Y_{p}}{R^{2} \rho_{c}}\right)^{a},\left(\frac{\rho_{c}}{\rho_{\text {III }}}\right)^{b},(G)^{c},\left(\frac{P V \times R P M}{Y_{p}}\right)^{d},\left(\frac{V}{R}\right)^{q}\right)=0
$$

From the general application procedure of the Buckingham $\mathrm{Pi}$ theorem, it can be combined to the existing dimensionless groups to form other dimensionless groups that are both in intuitively reasonable and at the same time useful in describing observed practice such as Reynolds and other classical dimensionless numbers. Then, moving the independent parameter $\boldsymbol{\eta}$ and its dimensionless group to the right handside, renaming the exponents and adding a proportionality constant, takes the form:

$$
\eta=C \times\left(\frac{Y p}{R^{2} \rho_{c}}\right)^{a} \times\left(\frac{\rho_{c}}{\rho_{m}}\right)^{b} \times(G)^{c} \times\left(\frac{P V \times R P M}{Y p}\right)^{d} \times\left(\frac{V}{R}\right)^{e}
$$

This (equation 4) is the derived form of the minimum efficiency of drilled-cuttings transport in annuli of deviated wells whilst drilling. From the derived Equation, the independent parameter " $\mathrm{dc}$ " has not appeared. This independent parameter is considered as a weak or minor variable, which was neglected by the dimensional analysis technique during the solution or analysis of the $\boldsymbol{\eta}$ problem.

Note that the minimum efficiency of drilled cuttings transport $(\boldsymbol{\eta})$ used in the model depend on the value of the minimum operating flow rate designed in the planning of the wells using a WELLPLAN ${ }^{\mathrm{TM}}$ software. The software depend on parameters taken from offsets to get the most effective value used to get the minimum operating flow rate (MOF).

\section{Determination of the unknown exponents and proportionality constant for the derived model using regression analysis technique}

The field data required for the input sets of model's equatioh variables in the derived model have been prepared by the author from the Gulf of Suez field region. Then, the linear regression analysis technique using the "Least-Squares method" was applied from the statistical computing system Using Microsoft Excel. However, this technique is a convenient method to determine the unknown exponents and proportionality constant of the model's equation, when Equation is linearized. The following are the linear regression analysis for the model's equation. In this equation, $C, a, b, c, d$ and $e$ are unknown parameters. Taking the logarithms of equation. Therefore,

$\ln (\eta)=\ln (C)+a \ln \left(\frac{V_{p}}{R^{2} \rho_{e}}\right)+\ln \left(\frac{P_{c}}{\rho_{m}}\right)+\operatorname{cln}(G)+d \ln \left(\frac{P V \times R P M}{Y_{p}}\right)+\ln \left(\frac{V}{R}\right) \quad 5$

This (equation 5) is an intrinsically linear model for regression analysis where $\ln (C)$ is the intercept of the 
best fitted line by the least squares method and $a, b$, $c, d$ and $e$ are the parameter estimates for the independent terms included in the model's equation. Also, Equation can be simplified as follows (equation 6):

$$
Y=\ln (c)+a X_{1}+b X_{2}+c X_{3}+d X_{4}+e X_{5}
$$

Where:

$$
Y=\ln (\eta), X_{1}=\ln \left(\frac{Y_{p}}{R^{2} \rho_{c}}\right), X_{2}=\ln \left(\frac{\rho_{c}}{\rho_{m}}\right), X_{3}=\ln (G), X_{4}=\ln \left(\frac{P V \times R P M}{Y_{p}}\right), X_{5}=\ln \left(\frac{V}{R}\right)
$$

Then the inputs values have been computed from the prepared field data from five different wells of Gulf of Suez field. And they are regressed by applying regression analysis of Microsoft Excel software.

\section{Applying the developed mathematical model on $20 \%$ of wells data}

By applying the regression on $20 \%$ of prepared field data, results can be got that the intercept and coefficients needed for the equation are:

$\ln (\mathrm{C})=5.090562, \mathrm{a}=0.105798, \mathrm{~b}=-0.03423, \mathrm{c}=-$ $0.19629, d=0.022214, e=0.015416$,

Thus, by substituting values of proportionality constant and exponents in (equation 6) which were obtained from the linear regression analysis as follows :

\section{$Y=5.090562+0.105798 X_{1}-0,03423 X_{2}-0,19629 X_{3}+0.022214 X_{4}$ $+0,015416 X_{5}$}

From this (equation 7) the final equation can be obtained using values to be substituted in (equation 3) which will be:

$$
\begin{aligned}
\eta=162.48 \times\left(\frac{Y p}{R^{2} \rho_{c}}\right)^{0.10579 g} \times\left(\frac{\rho_{c}}{\rho_{m}}\right)^{-0.03423} \times(G)^{-0.19629} \\
\times\left(\frac{P V \times R P M}{Y p}\right)^{0.022214} \times\left(\frac{V}{R}\right)^{0.015416}
\end{aligned}
$$

By applying the developed equation (equation 8) on well no.2 and comparing it to actual efficiencies values shown in (figure 1 ) from this figure show that error range from $15 \%$ to $35 \%$ which lead that data need more regression trial to get more representative equation for field data.

\section{Applying the developed mathematical model on $40 \%$ of wells data}

By applying the regression on $20 \%$ of prepared field data, results can be got that the intercept and coefficients needed for the equation are:

$\ln (C)=4.06027, a=0.030287, b=-0.37072, c=-$ $0.06752, d=0.160148, e=0.026338$,

Using these values to find the hole cleaning efficiency equation which will be:

$$
\begin{array}{r}
\eta=57.99 \times\left(\frac{\mathrm{Vp}}{\mathrm{R}^{2} \rho_{\mathrm{c}}}\right)^{0.030287} \times\left(\frac{\rho_{\mathrm{c}}}{\rho_{\mathrm{m}}}\right)^{-0.37072} \times(\mathrm{G})^{-0.06752} \\
\times\left(\frac{\mathrm{PV} \times \mathrm{RPM}}{\mathrm{Yp}}\right)^{0.160148} \times\left(\frac{\mathrm{V}}{\mathrm{R}}\right)^{0.026338}
\end{array}
$$

To verify (equation 9) by applying it on wells no.3, 4 between the developed hole cleaning efficiency come from the equation and the actual efficiency values shown (figure 2 ), from that the error range from $10 \%$ to $25 \%$, that show that using more data for regression decrease the value of error and make the equation more representative to be applied on field data. So one more trial using $80 \%$ of wells data will be applied in the next step.

\section{Applying the developed mathematical model on $80 \%$ of wells data}

In this step the developed mathematical model will be applied on $80 \%$ of prepared wells data, and then will use well no. 5 to verify the developed equation using the previous steps, results of regression can be got that the intercept and coefficients:

$\operatorname{Ln}(C)=4.53201, a=0.01634488, b=-$ $0.092391061, c=-0.194172714, d=0.013404218, e=$ 0.011105852 ,

Using these values to find the hole cleaning efficiency equation which will be:

$$
\begin{array}{r}
\eta=92.95 \times\left(\frac{Y p}{R^{2} \rho_{c}}\right)^{0.01634} \times\left(\frac{\rho_{c}}{\rho_{m}}\right)^{-0.09239} \times(G)^{-0.19417} \\
\times\left(\frac{P V \times R P M}{Y p}\right)^{0.013404} \times\left(\frac{V}{R}\right)^{0.0111058}
\end{array}
$$

To verify (equation 10) by applying it on wells no. 5 between the developed hole cleaning efficiency come from the equation and the actual efficiency values shown (figure 3 ), from that the error range is from $5 \%$ to $15 \%$, this error range is accepted.

Summarizing errors form the previous trials, the error values decrease using more field data (Table 1); so now (equation 10) represent field data and can be used as the final equation. In the next step the effect of each parameter in the equation on hole cleaning efficiency will be studied separately.

\section{Applying partial derivative principles to the developed model for evaluating the sensitivity of model's parameters:}

Applying partial differentiating with respect to each parameter to final equation, Thus, the resulting equations are given below:

$$
\begin{gathered}
\frac{\partial \eta}{\partial V}=\eta\left(\frac{e}{V}\right) \\
\frac{\partial \eta}{\partial R}=\eta\left(\frac{-2 a-e}{R}\right) \\
\frac{\partial \eta}{\partial Y p}=\eta\left(\frac{a-d}{Y p}\right) \\
\frac{\partial \eta}{\partial(P V)}=\eta\left(\frac{d}{P V}\right) \\
\frac{\partial \eta}{\partial R P M}=\eta\left(\frac{d}{R P M}\right) \\
\frac{\partial \eta}{\partial G}=\eta\left(\frac{c}{G}\right) \\
\frac{\partial \eta}{\partial \rho_{c}}=\eta\left(\frac{-a+b}{\rho_{c}}\right) \\
\frac{\partial \eta}{\partial \rho_{m}}=\eta\left(\frac{-b}{\rho_{m}}\right)
\end{gathered}
$$


The values of $\boldsymbol{\eta}$ have been computed by applying the regression Equation at the given values of these parameters for R, Yp, $\boldsymbol{\rho}_{\boldsymbol{c}}, \boldsymbol{\rho}_{\boldsymbol{m}}, \mathrm{G}, \mathrm{RPM}$ and $\mathrm{V}$. likewise, the values of $a, b, c, d$, and e where considered as mentioned before:
$\mathrm{a}=0.01634$
$b=-0.09239$
$c=-0.19417$
$\mathrm{d}=0.01340$
$\mathrm{e}=0.011106$ Then, the values of
sensitivity or parametric study of

$$
\frac{\partial \eta}{\partial R}, \frac{\partial \eta}{\partial Y p}, \frac{\partial \eta}{\partial \rho_{c}}, \frac{\partial \eta}{\partial \rho_{m}}, \frac{\partial \eta}{\partial G}, \frac{\partial \eta}{\partial R P M} \text { and } \frac{\partial \eta}{\partial V}
$$

were simulated. The simulation values of parametric study have been plotted versus the range minimum to maximum of R, Yp, $\boldsymbol{\rho}_{\boldsymbol{c}}, \boldsymbol{\rho}_{\boldsymbol{m}}, \mathrm{G}, \mathrm{RPM}$ and $\checkmark$ values, respectively.

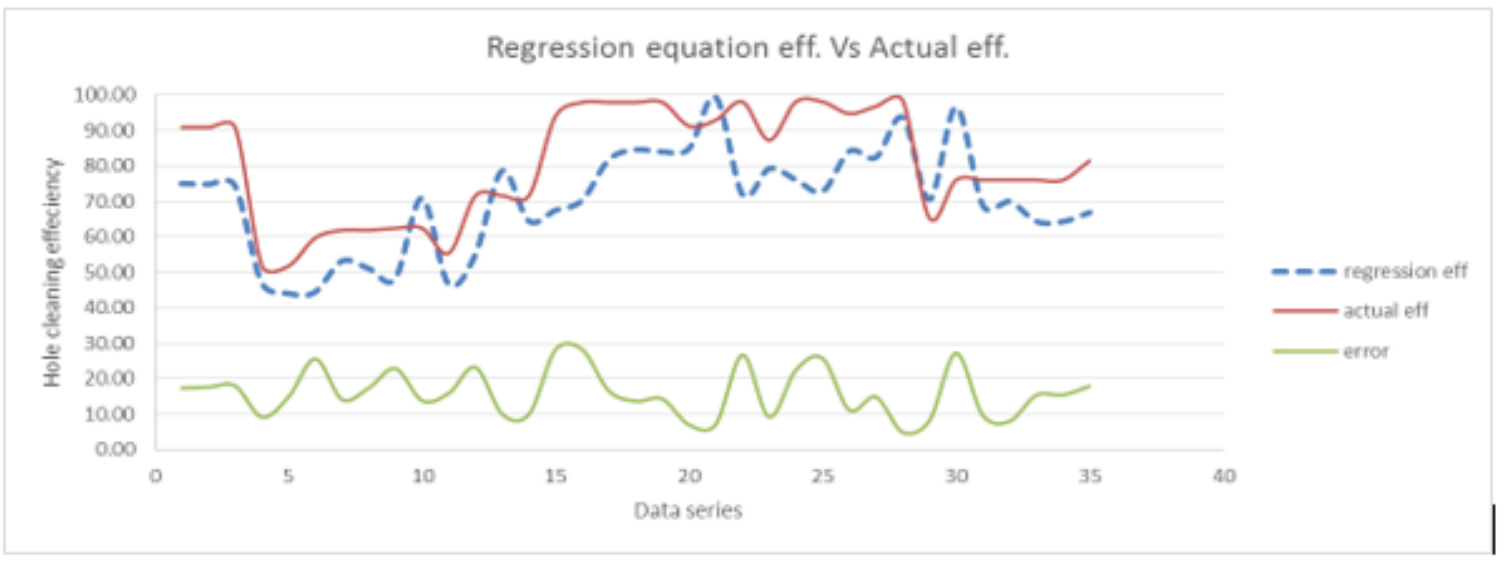

Figure 1 the regression equation results vs actual values of hole cleaning efficiency ( $20 \%$ of wells data)

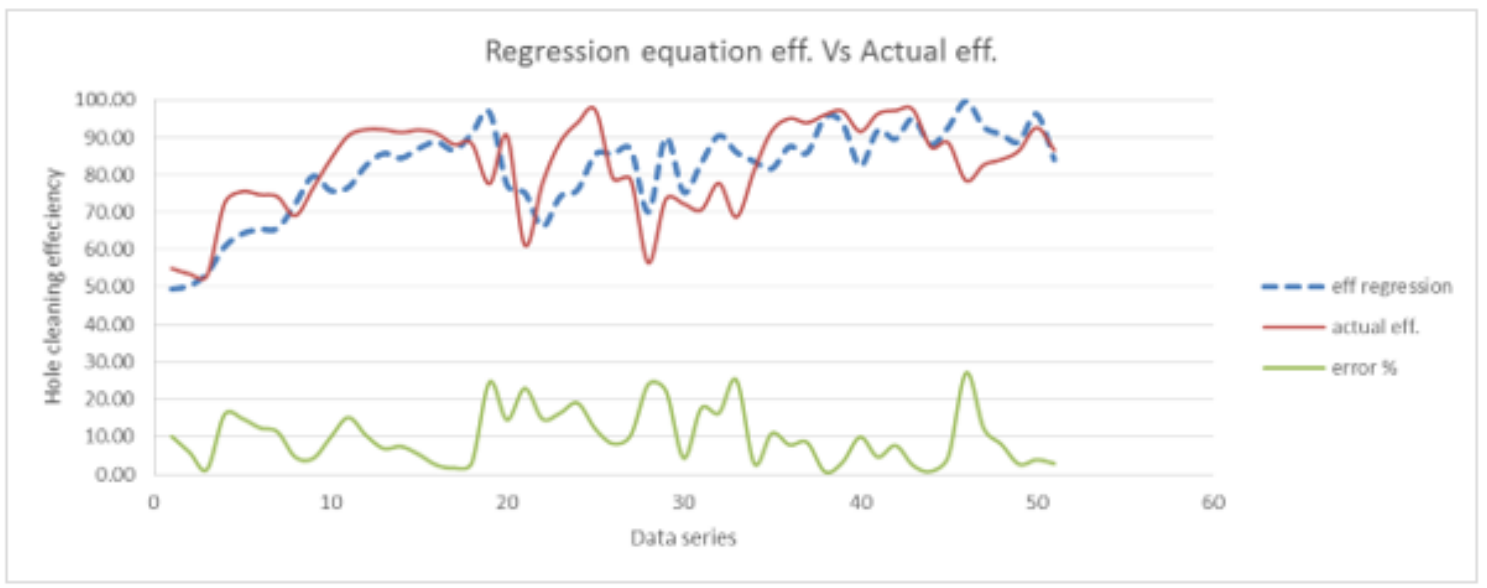

Figure 2 the regression equation results vs actual values of hole cleaning efficiency ( $40 \%$ of wells data)

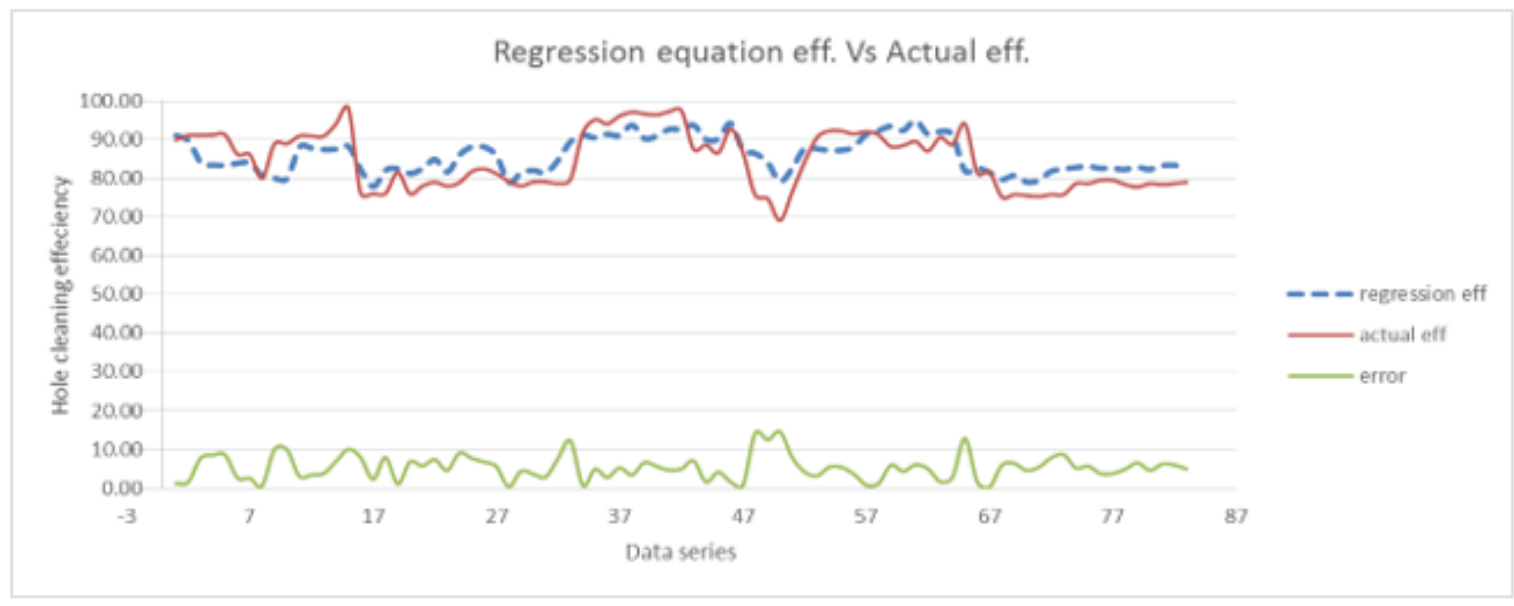

Figure 3 the regression equation results vs actual values of hole cleaning efficiency for the rest of data ( $80 \%$ of wells data) 
Table 1 error estimation for model trials.

\begin{tabular}{|c|c|c|c|}
\hline $\begin{array}{c}\text { Error estimation } \\
\text { between the actual } \\
\text { and model values }\end{array}$ & $\begin{array}{c}\text { Using 20\% of the data } \\
\text { and applying it on well } \\
\text { no.2 }\end{array}$ & $\begin{array}{c}\text { Using 40\% of the data } \\
\text { and applying it on wells } \\
\text { no.3,4 }\end{array}$ & $\begin{array}{c}\text { Using 80\% of the data } \\
\text { and applying it on rest } \\
\text { of wells data }\end{array}$ \\
\hline Min error & 4.803 & 0.690 & 0.259 \\
\hline average & 15.765 & 10.163 & 5.409 \\
\hline Max error & 35.194 & 27.178 & 14.592 \\
\hline$r$ (correlation coff.) & 0.778 & 0.840 & 0.912 \\
\hline R square value & 0.605 & 0.706 & 0.833 \\
\hline
\end{tabular}

\section{Discussion of the parametric study of the hole cleaning developed model}

Applying partial differentiation with respect to each parameter to equation, So, the resulting solutions are given below:

\section{Annular velocity $(V)$}

By applying the parametric differentiation for the final equation (equation 10) with respect to the annular velocity $(\boldsymbol{V})$ :

$$
\frac{\partial \eta}{\partial V}=\eta\left(\frac{e}{V}\right)
$$

Then by substitute with values of $\eta$, e and $\boldsymbol{V}$ in (equation 11), and then make the chart between the partial rate of change of the efficiency and the annular velocity with values of annular velocity, from (Figure 4) positive rates of change in hole cleaning efficiency, which mean there is a direct relation between $\boldsymbol{V}$ and the hole cleaning efficiency, the higher $\boldsymbol{V}$ representing a higher flow rates used the higher ability to overcome the cutting slip velocity, the higher hole cleaning efficiency.

The effect of flow rate represent the most important factor to have good hole cleaning, especially in deviated wells where cutting beds are formed in which the hole cleaning issues becomes a challenging problem, However, other drilling fluid properties and good drilling parameters help in control the optimum flow rate value needed to clean the hole, without affecting the well bore stability.

\section{Drilling rate (R)}

By applying the parametric differentiation for the final equation (equation 10) with respect to the drilling rate $(\boldsymbol{R})$ :

$$
\frac{\partial \eta}{\partial R}=\eta\left(\frac{-2 a-e}{R}\right)
$$

By applying (equation 12) to make the chart between rate of change of hole cleaning efficiency and drilling rate, from (Figure 5) negative rates of change can be got, which mean there is an inverse relation between ROP and the hole cleaning efficiency, the higher ROP the higher cuttings accumulation in hole, the lower hole cleaning efficiency.

Higher drilling rate will affect also making the desicion after insufficient hole cleaning took place that called "High-ROP Trap" 15 as in (figure 6). Drilling rate must be optimised before hole cleaning problem happens.

\section{Yield point (Yp)}

By applying the parametric differentiation for the final equation (equation 10) with respect to the Mud yield point $(\mathrm{Yp})$ :

$$
\frac{\partial \eta}{\partial Y p}=\eta\left(\frac{a-d}{Y p}\right)
$$

By applying (equation 13) to make the chart between rate of change of hole cleaning efficiency and mud yield point, from (Figure 7) positive rates of change can be got, which mean there is a direct relation between $\boldsymbol{Y} \boldsymbol{p}$ and the hole cleaning efficiency, the higher $\boldsymbol{Y p}$ the higher drilling fluid carrying capacity, the higher hole cleaning efficiency.

The following (figure 8) taken from well was drilled from a deep-water, tensioned-leg platform in the Mississippi Canyon area 15 which shows increasing in $E C D$ values as $Y p$ decrease which indicate insufficient hole cleaning and vice versa.

\section{Plastic viscosity}

By applying the parametric differentiation for the final equation (equation 10) with respect to the Mud plastic viscosity (PV):

$$
\frac{\partial \eta}{\partial(P V)}=\eta\left(\frac{d}{P V}\right)
$$

By applying (equation 14) to make the chart between rate of change of hole cleaning efficiency and plastic viscosity, from (Figure 9) positive rates of change can be got, which mean there is a direct relation between $(\boldsymbol{P} \boldsymbol{V})$ and the hole cleaning efficiency, So According to this study, increasing the plastic viscosity of the mud resulted in increasing the amount of recovered cuttings.

However, researchers offer various ideas about the effect of viscosity on hole cleaning, Some researchers such as Okrajni and Azar 7 believed that raising viscosity of the drilling fluid deteriorates hole cleaning, because type of flow regime changes 
from turbulent flow to laminar flow; and it has been proved that cuttings can be better displaced in turbulent flow than laminar flow. On the other hand, there are also some investigators such as Ford et al. ${ }^{8}$, claimed that improvement in hole cleaning occurs as viscosity increases.

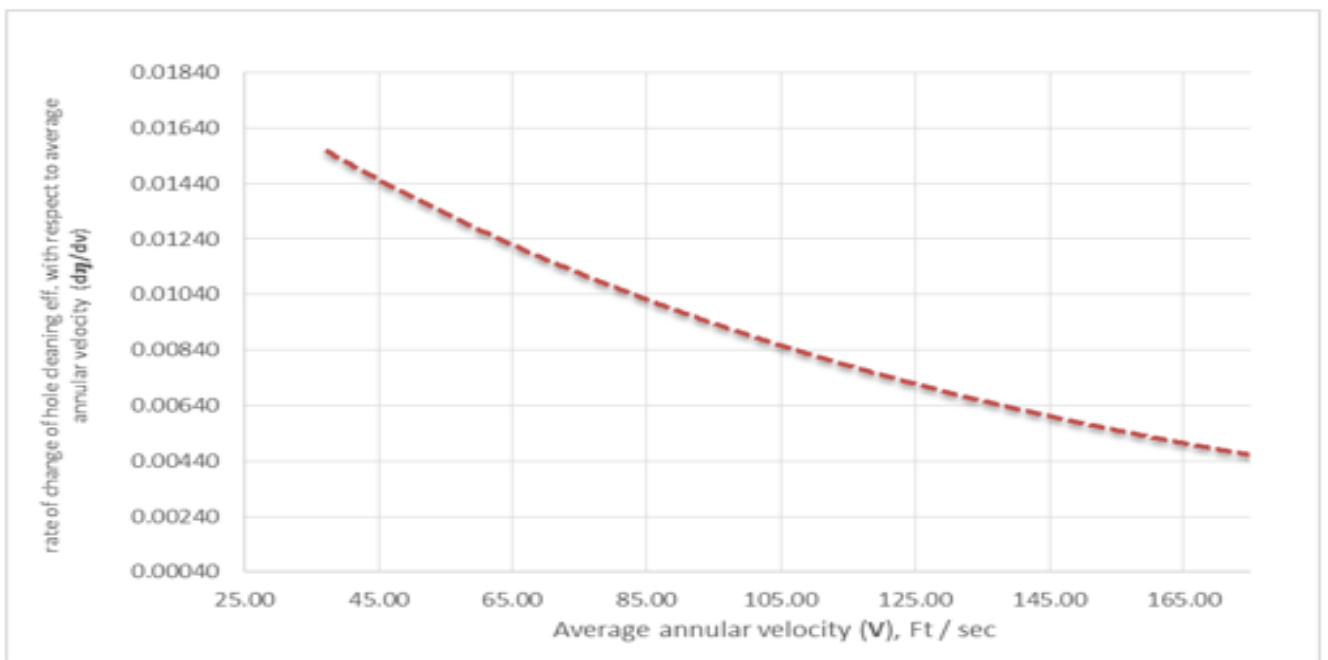

Figure 4 the rate of change of hole cleaning eff. with respect to average annular velocity $(\mathrm{d} \eta / \mathrm{dv})$ vs average annular velocity $(\mathrm{V})$.

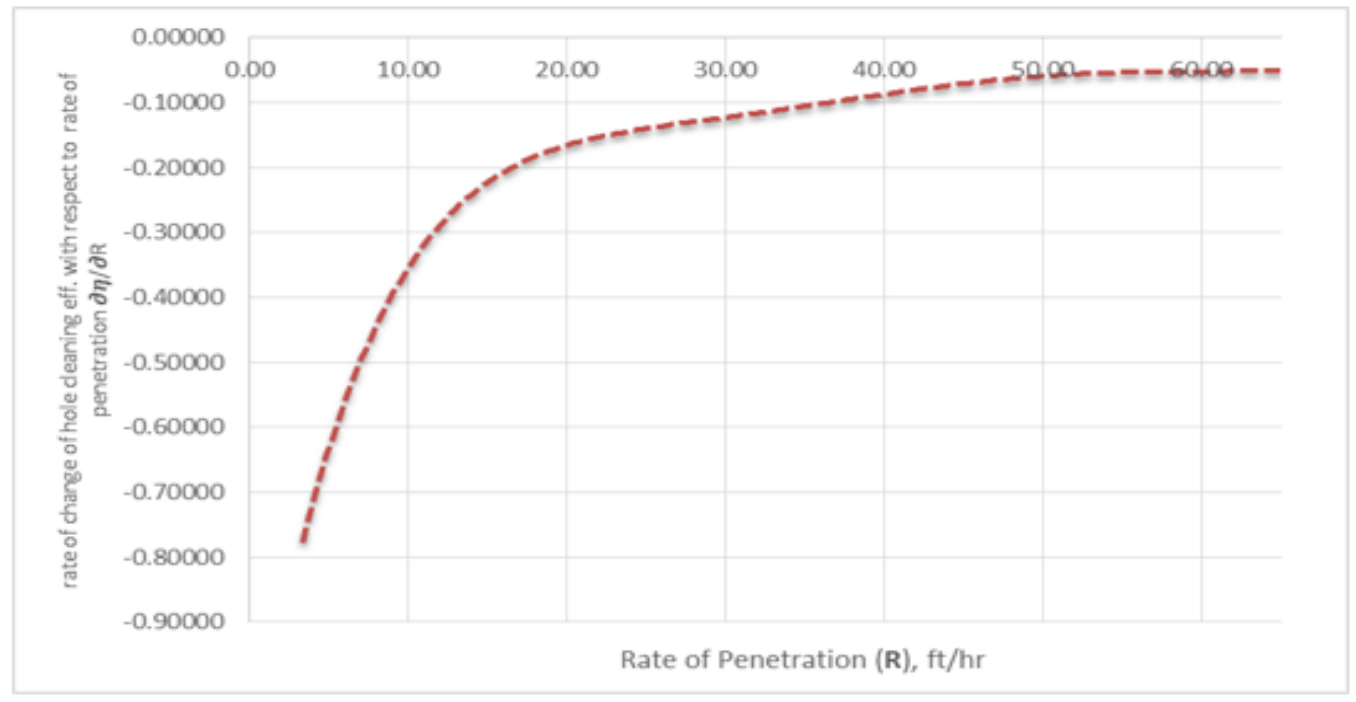

Figure 5 the rate of change of hole cleaning eff. with respect to rate of penetration $(\partial \eta / \partial R)$ vs rate of penetration $(R)$

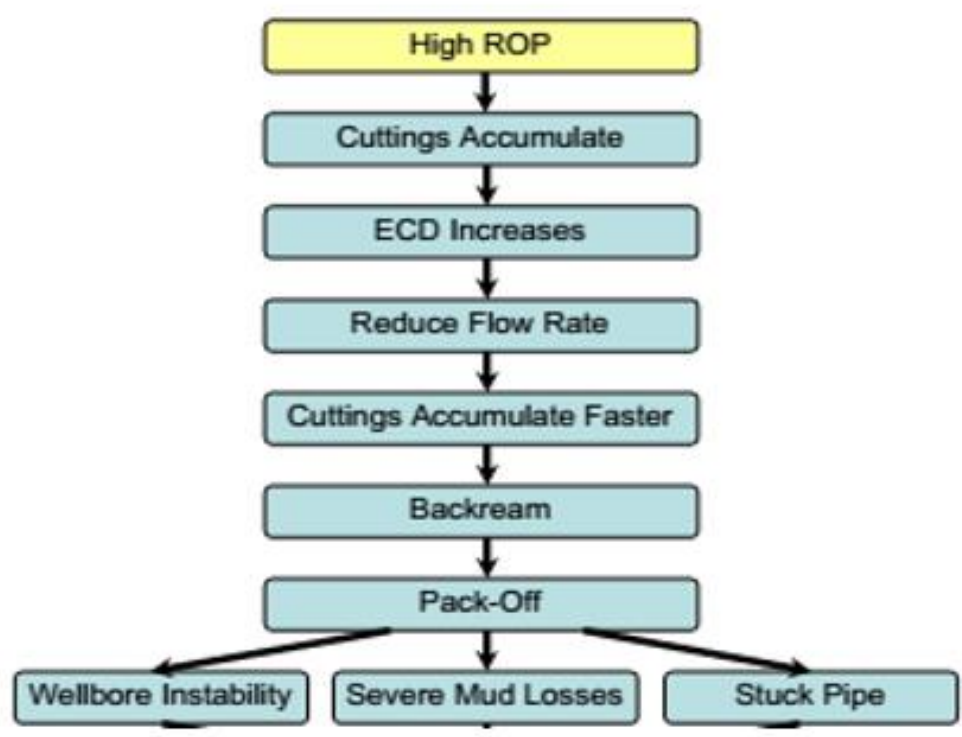

Figure 6 Graphic representation of the "High-ROP Trap" [15]. 


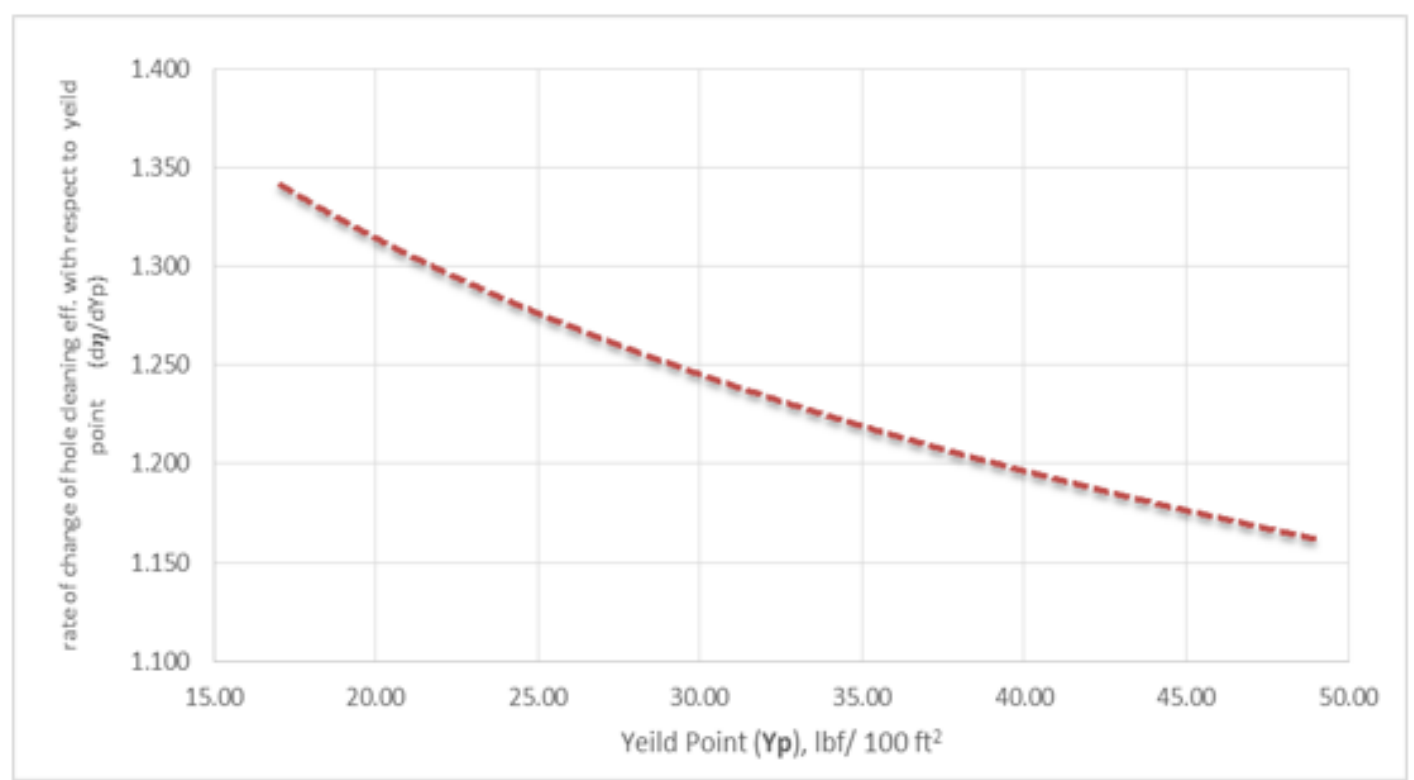

Figure 7 the rate of change of hole cleaning eff. with respect to drilling fluid yield point $\left(\partial \eta / \partial \gamma_{\mathrm{p}}\right)$ vs drilling fluid yield point.

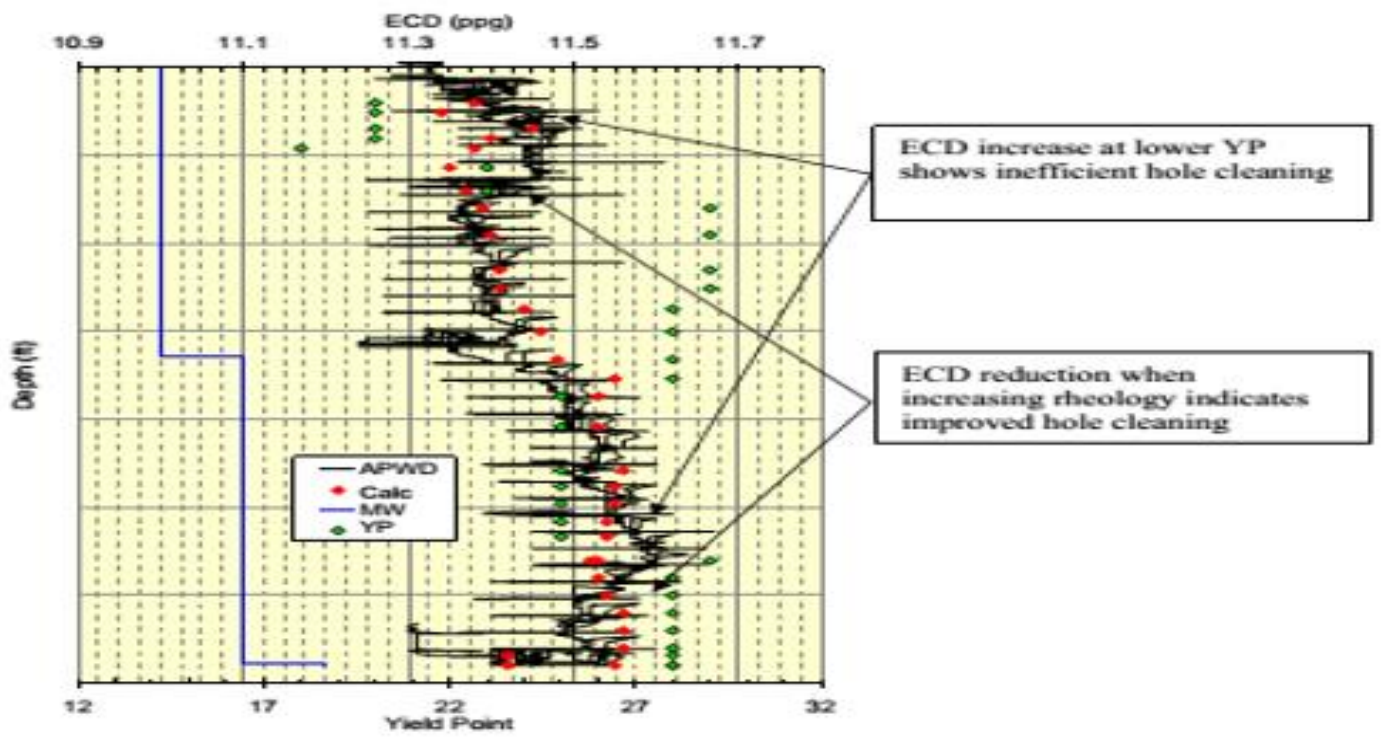

Figure 8 Measured and calculated ECD, mud weight and yield point vs depth [15].

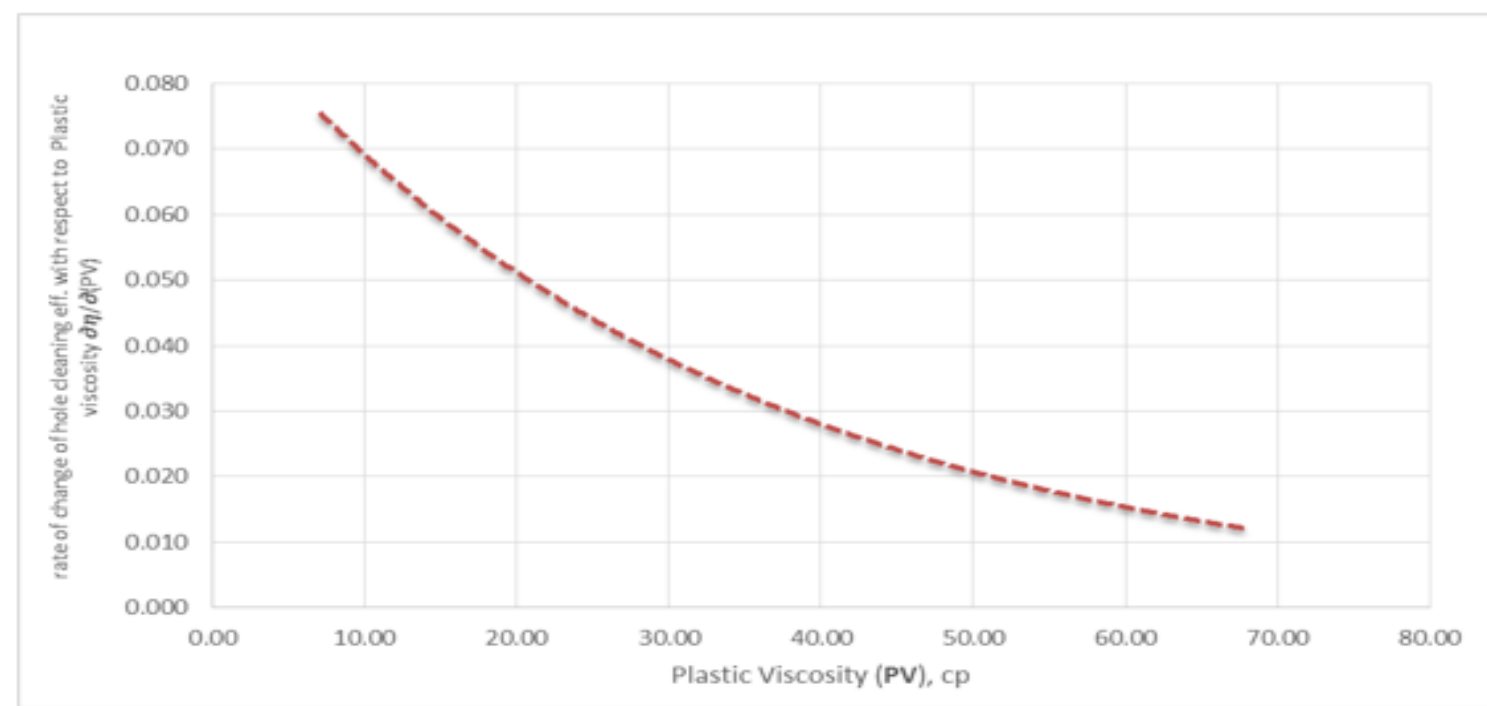

Figure 9 the rate of change of hole cleaning eff. with respect to drilling fluid plastic viscosity $(\partial \eta / \partial \mathrm{PV})$ vs drilling fluid plastic viscosity (PV). 


\section{Rotation speed (RPM)}

By applying the parametric differentiation for the final equation (equation 10) with respect to string rotation speed (RPM):

$\frac{\partial \eta}{\partial \mathrm{RPM}}=\eta\left(\frac{\mathrm{d}}{\mathrm{RPM}}\right)$

By applying (equation 15) to make the chart between rate of change of hole cleaning efficiency and rate of penetration (RPM), from (Figure 10) positive rates of change can be got, which mean there is a direct relation between (RPM) and the hole cleaning efficiency, the higher (RPM) the higher ability for the drilling fluid to clean cuttings in the low side, the higher hole cleaning efficiency.

The rotation of the drill string contribute effectively in hole cleaning especially in critical angle wells where The cutting beds on the low side of the hole is removed by the contribution of the mechanical agitation and the exposure to higher drilling fluids velocities when the string moves to the high side of the hole. However, there are some limitations for the whirling motion. When using the down hole motor, during the sliding mode, the string is in stationary which affect the cuttings removal. Pipe failures caused by the cyclic stresses due to pipe rotation. Casing wear and mechanical destruction of the open hole are other problems which can be caused by the pipe rotation.

\section{Angle factor (G)}

By applying the parametric differentiation for the final equation (equation 10) with respect to angle factor $(G)$ :

$$
\frac{\partial \eta}{\partial G}=\eta\left(\frac{c}{G}\right)
$$

By applying (equation 16) to make the chart between rate of change of hole cleaning efficiency and angle factor, from (Figure 11) negative rates of change can be got, Which mean there is an inverse relation between angle factor (G) and the hole cleaning efficiency, the higher $(G)$ the higher cuttings accumulation in low side, the lower hole cleaning efficiency.

The hole cleaning is difficult when drilling deviated wells. It has been mentioned that the maximum flow rate requirements for cleaning are reached at the angle between $65^{\circ}$ to $67^{\circ}$. Sudden shutdown of the mud pumps when drilling through deviated wells of an inclination angle around $25^{\circ}$ to $45^{\circ}$ can cause cuttings sloughing to the bottom and may lead to mechanical pipe sticking.

\section{Cutting density $\left(\rho_{c}\right)$}

By applying the parametric differentiation for the final equation (equation 10 ) with respect to cuttings density $\left(\boldsymbol{\rho}_{\boldsymbol{c}}\right)$ :

$$
\frac{\partial \eta}{\partial \rho_{c}}=\eta\left(\frac{-a+b}{\rho_{c}}\right)
$$

Similarly the chart is got by applying (equation 17), which mean there is an inverse relation between drilled cuttings density $\left(\boldsymbol{\rho}_{c}\right)$ and the hole cleaning efficiency, the higher $\left(\boldsymbol{\rho}_{\boldsymbol{c}}\right)$ the lower cutting velocity by effect of gravity, the lower hole cleaning efficiency.

Generally the cuttings characteristics like cuttings size and shape are related to the bit used during operations. The size, shape and specific gravity of cuttings affect the dynamic behavior when flowing into the drilling fluids. Grinding and breakage by drill string rotating make it impossible to control cuttings shape and size. In directional well drilling, cuttings are more difficult to transport, but with adequate viscosity and pipe rotation, small particles stay in suspension which make them easier to transport.

\section{Mud weight $\left(\rho_{m}\right)$ :}

By applying the parametric differentiation for the final equation (equation 10) with respect to Mud weight $\left(\boldsymbol{\rho}_{\boldsymbol{m}}\right)$ :

$$
\frac{\partial \eta}{\partial \rho_{m}}=\eta\left(\frac{-b}{\rho_{m}}\right)
$$

By applying (equation 18) to make the chart between rate of change of hole cleaning efficiency and drilling fluid density, from (Figure 13) positive rates of change can be got, which mean there is a direct relation between $\left(\boldsymbol{\rho}_{m}\right)$ and the hole cleaning efficiency, the higher $\left(\boldsymbol{\rho}_{\boldsymbol{m}}\right)$ the higher effect of buoyancy force acting on the cuttings, the lower cuttings slip velocity, the higher hole cleaning efficiency. However, mud weight in excess of what is needed to balance formation pressures has a negative impact on the ROP (figure 14); therefore, it should never be increased for hole-cleaning purposes[16].

\section{Conclusions}

The following are the conclusions which were drawn from this study:

- Using field data to develop a mathematical model using Buckingham $\mathrm{Pi}$ theorem, dimensionless parameters are prepared from the factors affecting the hole cleaning to form one equation which can be used to calculate the hole cleaning efficiency for vertical and deviated oil wells drilling applications.

- The developed model regression applied by using $20 \%, 40 \%$ and $80 \%$ of data to get final equation to be representative for hole cleaning efficiency to be used for other field wells, and it is found that with more regression for the field data, the less errors can be got (Table 1) and the final equation using $80 \%$ of field data is ready to make test of validity using additional field data.

- After making a test of validity for the developed equation, the developed model was evaluated parametrically to measure the effect on the model of changing one of the equation parameters with respect to hole cleaning efficiency, which is referred to as sensitivity analysis or parametric study. 
- From this parametric study, it was found that the hole cleaning efficiency increases as the following parameters increase:
a) Average annular velocity (V) in $\mathrm{ft} / \mathrm{sec}$.
b) Mud weight $\left(\boldsymbol{\rho}_{\mathrm{m}}\right)$, in ppg.
c) Yield point (Yp), in lbf/100 $\mathrm{ft}^{2}$.
d) Plastic viscosity (PV) in cp.
e) Drill string rotation (RPM) in $\mathrm{rot} / \mathrm{min}$.

Also, the hole cleaning efficiency decreases when the following parameters increase:

a) Drilling rate of formation unit $(\mathbf{R})$ in $\mathrm{ft} / \mathrm{hr}$.

b) Drilled - cuttings density $\left(\boldsymbol{\rho}_{\mathrm{c}}\right)$ in ppg.

c) Angle factor (G).
- The statistical model is a practical, empirical technique to estimate hole cleaning efficiency in a wide variety of onshore and offshore drilling regions.

- Also, the statistical model provides useful information for the design of drilling operations of deviated wells to insure adequate transport of drilled cuttings. Actually, this model can be used for design the most important hole cleaning parameters during drilling a deviated well such as:

a) Mud weight.

b) Rheological properties of mud in terms of yield point.

c) Average mud flow rate.

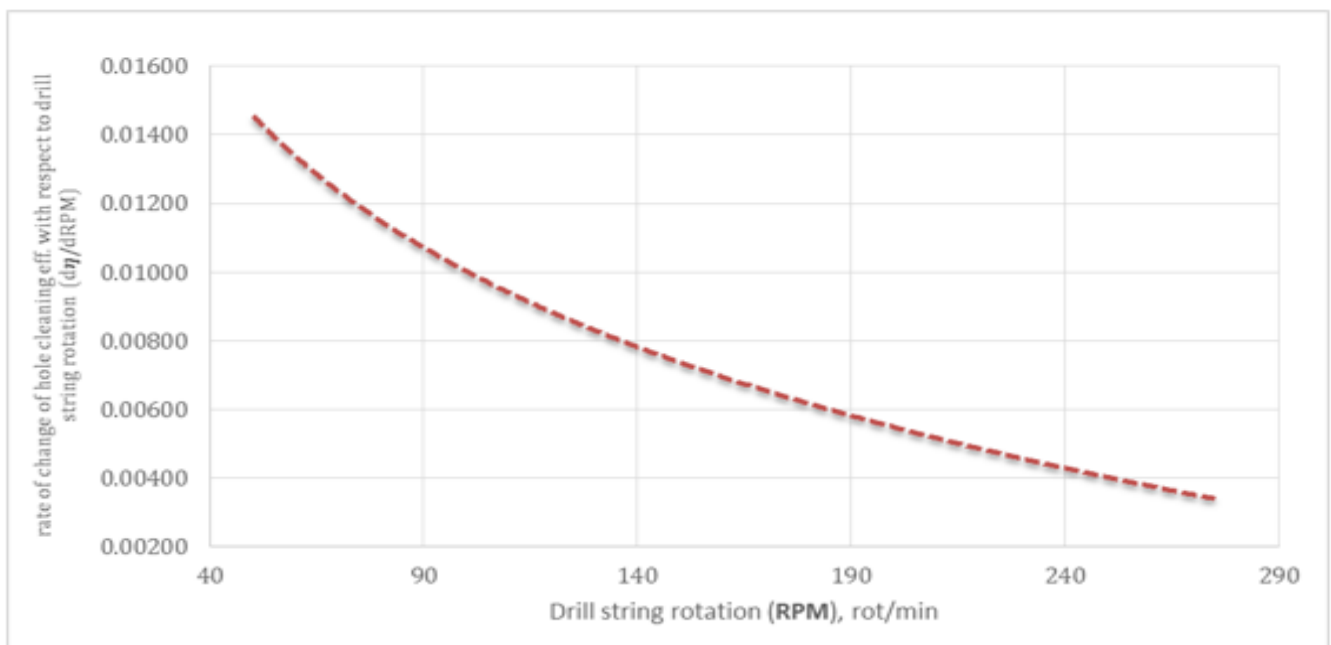

Figure 10 the rate of change of hole cleaning eff. with respect to drill string rotation $\boldsymbol{\partial \eta} / \partial \mathrm{RPM}$ vs string rotation ( $\mathrm{rpm})$

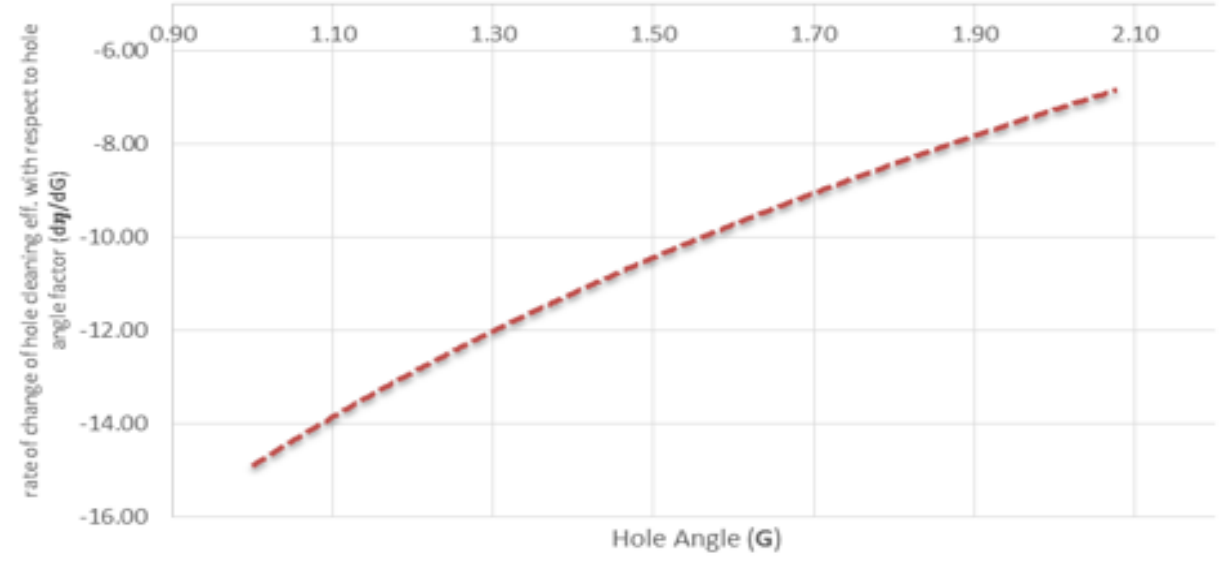

Figure $\mathbf{1 1}$ the rate of change of hole cleaning eff. with respect to hole angle factor $\boldsymbol{\partial \eta} / \boldsymbol{\partial} \mathrm{G}$ vs Hole angle factor (G) 


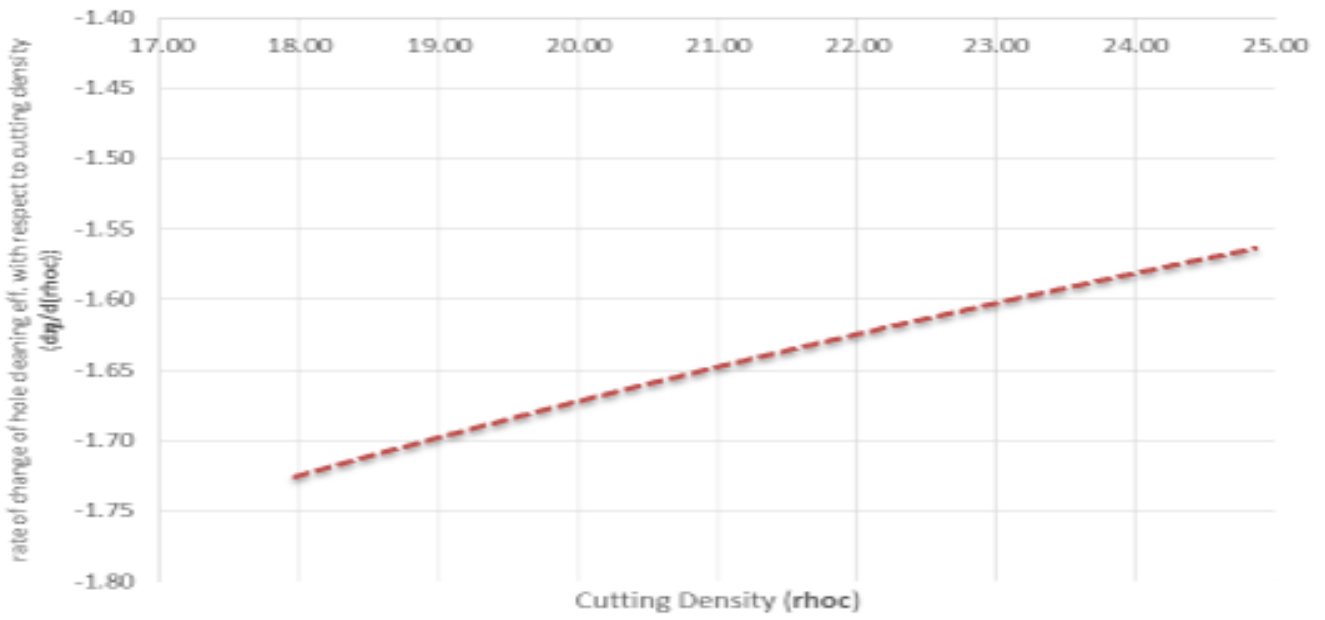

Figure 12 the rate of change of hole cleaning eff. with respect to drilled cuttings density $\mathrm{d} \boldsymbol{\eta} / \mathrm{d}$ (rhoc) vs drilled cuttings density $\left(\rho_{\mathrm{c}}\right)$

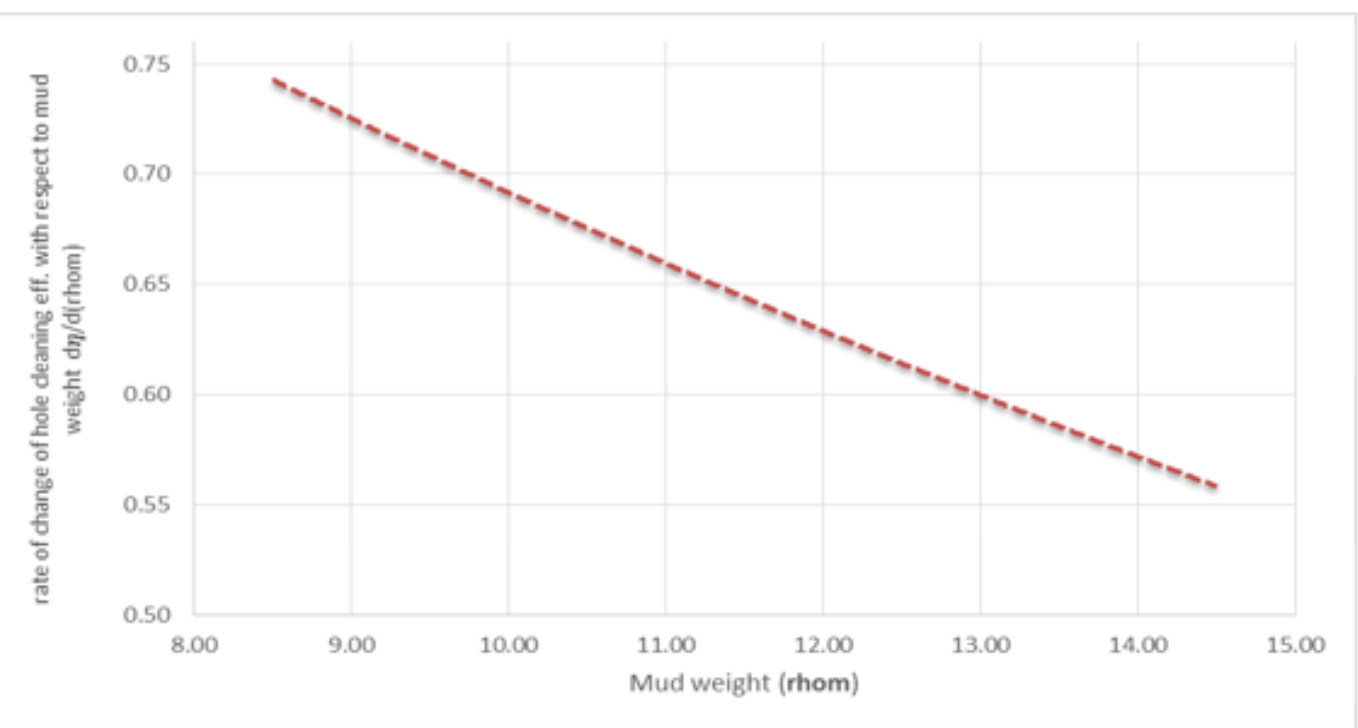

Figure 13 the rate of change of hole cleaning eff. with respect to Mud weight $d \boldsymbol{\eta} / \mathrm{d}$ (rhom) vs drilling Mud weight $\left(\rho_{m}\right)$

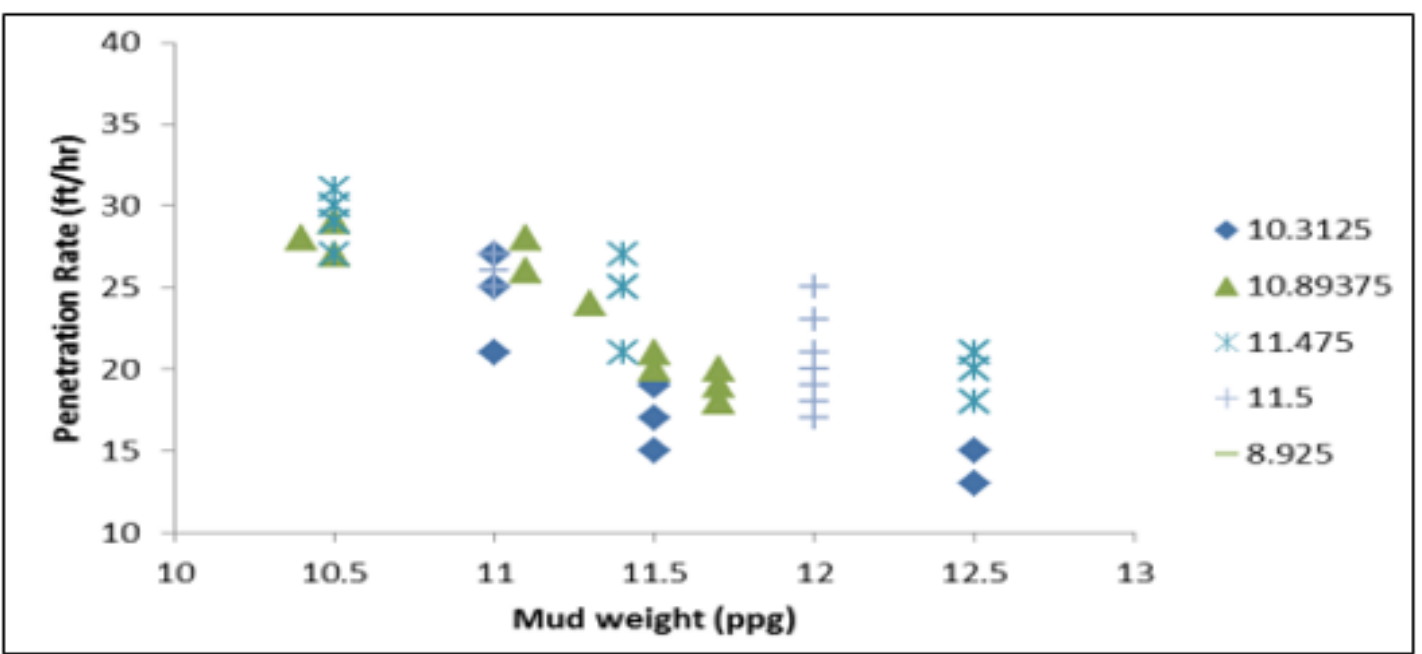

Figure 14 Penetration Rate vs. mud weight -water based mud [16]. 


\section{Recommendations}

- Buckingham Pi theorem is very useful statistical model for many drilling applications, by applying dimensionless parameters from independent parameters and see the effect of each on dependent one, as example using model for studying more parameters like drill pipe eccentricity.

- The developed-statistical model for hole cleaning efficiency can and should be used on more drilling fields worldwide especially horizontal wells worldwide.

- This statistical model can be used as a predictive tool and as a design tool for planning the most important mud parameters such as mud weight and rheological properties in terms of yield point. Also, this model should be used for efficient mud hydraulics preplanning.

\section{References}

[1] Farahat, M.S. (2001), "A Statistical Model for Annular Cutting Transport Efficiency during Drilling Deviated Wells", Journal of Engineering and Applied Science, Faculty of Engineering, Cairo University, Vol. 48, NO. 3.

[2] Peden, J.M., Ford, J.T., and Oyeneyin, M.B. (1990), "Comprehensive Experimental Investigation of Drilled Cuttings Transport in Inclined Wells Including the Effects of Rotation and Eccentricity," paper SPE-20925MS, published in European Petroleum Conference, The Hague, Netherlands.

[3] Larsen, T.I., Pilehvari, A.A., and Azar, J.J. (1997), "Development of a New Cuttings Transport Model for High-Angle Wellbores Including Horizontal Wells," paper SPE-25872-PA, published in SPE Annual Technical Conference and Exhibition, Vol. 12.

[4] Rudi Rubiandini, R.S. (1999), "Equation for Estimating Mud Minimum Rate for Cuttings Transport in an Inclined-Until-Horizontal Well", paper SPE-57541-MS, published in SPE/IADC Middle East Drilling Technology Conference, 8-10 November, Abu Dhabi, United.

[5] Hussaini, S.M. And Azar, J.J. (1983), “Experimental Study of Drilled Cuttings Transport Using Common Drilling Muds," paper SPE-10674-PA, published in Society of Petroleum Engineers Journal Vol. 23.

[6] Tomren, P.H., lyoho, A.W., and Azar, J.J. (1986) "Experimental Study of Cuttings Transport in Directional Wells," paper SPE-12123-PA, published in SPE Drilling Engineering (SPEDE), Vol.1, Issue 01.

[7] Okrajni, S.S. and Azar, J.J. (1986), "The Effects of Mud Rheology on Annular Hole Cleaning in Directional Wells," paper SPE-14178-PA, published in SPE Drilling Engineering (SPEDE), Vol. 1, Issue 04

[8] Ford J.T., Paden, J.M., Oyeneyin, M.B., Erhu Gao and Zarrough, R. (1990), "Experimental Investigation of Drilled Cuttings Transport in Inclined Boreholes," paper SPE-20421-MS, published in SPE Annual Technical Conference and Exhibition, 23-26 September, New Orleans, Louisiana.

[9] Belavadi, M.N. and Chukwu, G.A. (1994), “Experimental Study of the Parameters Affecting Cutting Transportation in a Vertical Wellbore Annulus," paper
SPE-27880-MS, presented at SPE Western Regional Meeting, 23-25 March, Long Beach, California.

[10] Rasi, M. (1994), "Hole Cleaning in Large, High-Angle Wellbores," paper SPE-27464-MS, published in SPE/IADC Drilling Conference, 15-18 February, Dallas, Texas.

[11] Martins, A.L., Sa, C.H.M., Lourenco, A.M.F., Freire, L.G.M., and Campos, W. (1996), "Experimental Determination of Interfacial Friction Factor in Horizontal Drilling With a Bed of Cuttings", paper SPE36075-MS presented at SPE Latin America/Caribbean Petroleum Engineering Conference, 23-26 April, Portof-Spain, Trinidad.

[12] Sanchez, R.A., Azar, J.J., Bassal, A.A., and Martins, A.L. (1999), "Effect of Drillpipe Rotation on Hole Cleaning during Directional-Well Drilling", paper SPE-56406-PA published in SPE Journal Vol. 4 Issue 02.

[13] Walker, S. and Li J. (2000), "The Effects of Particle Size, Fluid Rheology, and Pipe Eccentricity on Cuttings Transport", paper SPE-60755-MS published in SPE/ICOTA Coiled Tubing Roundtable, 5-6 April, Houston, Texas.

[14] Yu, M., Melcher, D., Takach, N., Miska, S.Z., and Ahmed, R. (2004), "A New Approach to Improve Cuttings Transport in Horizontal and Inclined Wells", paper SPE90529-MS presented at SPE Annual Technical Conference and Exhibition, 26-29 September, Houston, Texas.

[15] Aldea, C., Iyoho, A. W., and Zamora, M. (2005) "Hole Cleaning: the Achilles' Heel of Drilling Performance?" AADE 2005 National Technical Conference and Exhibition (AADE-05-NTCE), held at the Wyndam Greenspoint in Houston, Texas.

[16] Akpabio, J. U., Inyang, P. N. and Iheaka, C. I. (2015) "The Effect of Drilling Mud Density on Penetration Rate" International Research Journal of Engineering and Technology (IRJET) Volume: 02 Issue: 09.

\section{Nomenclature}

C Unknown proportionality constant generated by dimensionless analysis.

dc Cuttings diameter, (in).

$\boldsymbol{\pi}$ Pi- terms.

$\boldsymbol{\eta} \quad$ Hole cleaning efficiency, (\%).

ECD Equivalent circulating density, (ppg).

G Coefficient relating to hole deviation angle.

PV Plastic Viscosity, (cp).

Q Volumetric flow rate, (gpm)

$\mathrm{R}, \mathrm{ROP}$ Rate of penetration, (ft/hr).

$\rho$ c Drilled cuttings density, (ppg).

om Mud density, (ppg)

$\mathrm{V} \quad$ Average annular velocity, (ft/min).

$X \quad$ Independent variable.

Y Dependent variable.

MOF Minimum operating flow rate, (gpm)

YP Yield point, (lbf/ $100 \mathrm{ft}^{2}$ ).

RPM Drill string rotation, (rot/min). 